\title{
Usefulness of presepsin in the diagnosis of sepsis in patients with or without acute kidney injury
}

\author{
Yoshihiko Nakamura*, Hiroyasu Ishikura, Takeshi Nishida, Yasumasa Kawano, Rie Yuge, Reiko Ichiki and Akira Murai
}

\begin{abstract}
Background: Presepsin is useful for differentiating sepsis from non-infection related systemic inflammatory response syndrome. However, there are no studies investigating the usefulness of presepsin in diagnosing sepsis involving patients with acute kidney injury (AKI). The purpose of this study is to determine levels of blood presepsin in patients with or without sepsis and among non-AKI patients or patients with different degrees of AKI severity.

Methods: This is a single center retrospective study. 247 patients admitted to the ICU between June 2010 and October 2012 were analyzed for their presepsin levels. We classified the patients into non-AKI and AKI according to the RIFLE (Risk, Injury, Failure, and Loss of kidney function and End-stage kidney disease or simply Loss and ESKD) criteria. We then sub-classified the patients in each group into either non-sepsis or sepsis sub-group and analyzed the accuracy of diagnosing sepsis based on their levels of presepsin.

Results: The number of patients for each group was: non-AKI, 112; under AKI: Risk, 50; Injury, 36; Failure, 42; Loss and ESKD, 7. The levels of presepsin in sepsis groups were significantly higher than that in the non-sepsis group among the non-AKI, Risk and Injury patients ( $p<0.0001, p<0.01, p<0.01$, respectively). However, no significant difference in the level of presepsin between non-sepsis and sepsis groups among patients with Failure. In the receiver operating characteristic (ROC) analysis, the area under the curve (AUC) was 0.784 in the non-AKI group and 0.698 in the AKI comprising Risk, Injury and Failure groups. AUC value for non-AKI was not significantly different from that of AKI $(p=0.200)$. When $670 \mathrm{pg} / \mathrm{mL}$ was used as the cutoff value for presepsin, sensitivity and specificity were $70.3 \%$ and $81.3 \%$, respectively. When $864 \mathrm{pg} / \mathrm{mL}$ was used as the cutoff value for presepsin, sensitivity and specificity were $71.4 \%$ and $63.8 \%$, respectively.

Conclusions: Presepsin level can be a reliable indicator of sepsis not only among non-AKI patients but also patients with less severe forms of AKI. However, it may not be a reliable indicator of sepsis in patients with a more advanced form of AKI.
\end{abstract}

Keywords: Presepsin, Acute kidney injury, RIFLE criteria, Sepsis, Diagnosis

\section{Background}

Since the definition of systemic inflammatory response syndrome (SIRS) was proposed in 1991, several clinical trials on sepsis diagnosis and treatment have been conducted using the definition of sepsis given by the American College of Chest Physicians/Society of Critical Care Medicine (ACCP/SCCM) [1]. Many studies have reported that early treatment of sepsis using appropriate antibiotics improved the prognosis and increased the survival rate in severe sepsis or septic shock patients

\footnotetext{
* Correspondence: pdmxy827@yahoo.co.jp

Department of Emergency and Critical Care Medicine, Faculty of Medicine, Fukuoka University, 7-45-1 Nanakuma, Jonan-ku, Fukuoka 814-0180, Japan
}

[2-4]. Various biomarkers have been studied for diagnosing sepsis [5]. Currently, procalcitonin (PCT) is used as a marker to diagnose sepsis or severe sepsis. In comparison to other markers that have traditionally been reported, PCT gives a high rate of specificity for sepsis diagnosis [6]. However, the concentration of PCT in the human blood is elevated in various conditions, such as in severe trauma, surgical invasive procedures, and critical burn injury, which leads to SIRS. It is also necessary to be aware of false-positive results [7]. Therefore, more reliable biomarkers for the diagnosis of sepsis are needed. Another marker is interleukin-6 (IL-6), which may be detectable in the early stages of 
infection and bacteremia [8,9]. Recently Endo et al. [10] reported that presepsin is a highly specific marker for diagnosis of bacterial infections in comparison to other sepsis markers (PCT, IL-6). However, the presepsin levels above the cutoff value in patients with chronic renal failure must be interpreted with caution. Additionally, there are no studies investigating the usefulness of presepsin for assessing patient with acute kidney injury (AKI). In this study we attempted to clarify the diagnostic accuracy of sepsis using the presepsin level according to AKI severity of the patients.

\section{Methods}

This study was conducted as a single center retrospective study. In our hospital, patient's extra blood samples were stored for research purposes and informed consent from patients taken. Whole blood was collected with EDTA-2 $\mathrm{K}$ as an anticoagulant using a conventional blood collection tube (TERUMO, Japan). Whenever extra blood sample is available, the blood is centrifuged at $1400 \mathrm{~g}$ for $5 \mathrm{~min}$ and the serum kept at $-70^{\circ} \mathrm{C}$ for future use. In this present study, we enrolled all qualified patients with available stored serum samples. The study protocol was approved by the institutional review board of Fukuoka
University Hospital according to the Declaration of Helsinki. The samples were from patients' blood collected $24 \mathrm{hr}$ upon admission to the ICU of Fukuoka University Hospital between June 2010 and October 2012. There were 247 patients with stored samples and we included all for presepsin measurement. We grouped the patients into non-AKI or AKI according to the RIFLE (Risk, Injury, Failure, Loss of kidney function and Endstage kidney disease: Loss and ESKD) criteria [11]. We then classified patients in each group as either sepsis or non-sepsis and analyzed the accuracy of diagnosing sepsis based on the levels of presepsin. Sepsis diagnosis (include severe sepsis and septic shock) was defined by ACCP/ SCCM Consensus Conference Committee [1]. Patients' classification, enrollment into the study and exclusion from the study are shown Figure 1.

\section{Presepsin measurement}

The frozen serum was allowed to melt to become liquid at room temperature before presepsin testing. Presepsin concentration in blood was measured with a compact automated immunoanalyzer, PATHFAST ${ }^{\circ}$, based on a chemiluminescent enzyme immunoassay (CLEIA) (Mitsubishi Chemical Medience, Japan) [12,13].

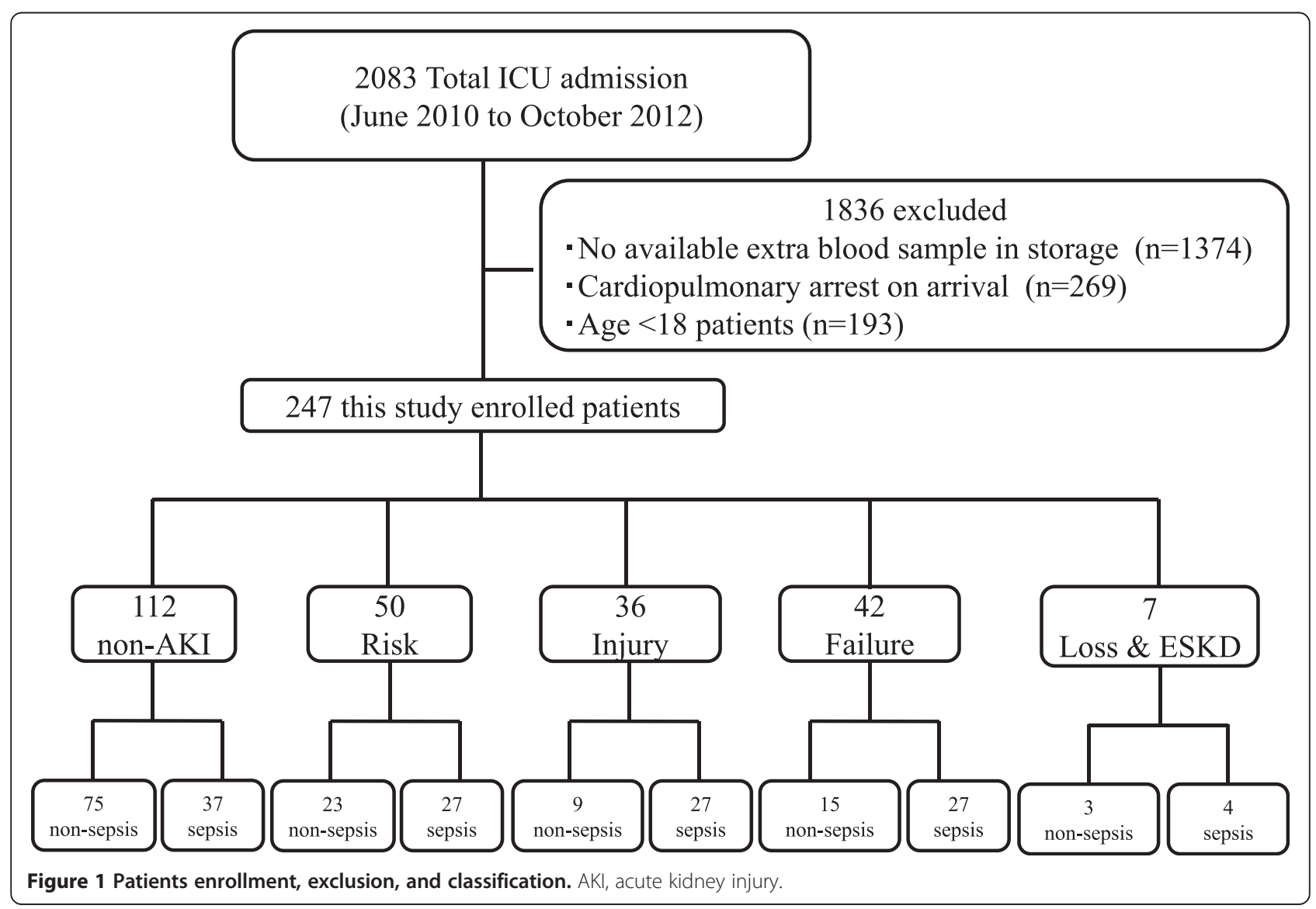




\section{Classification of acute kidney injury}

Oliguria and RIFLE were the most frequently used criteria to define AKI. In particular, RIFLE criteria were formulated to make a clearer classification of AKI among patients having renal problems [14]. Therefore, we used RIFLE criteria for AKI diagnosis in this study.

The patient's degree of AKI according to the RIFLE criteria (Table 1) [11] is determined after the urine output for the first $24 \mathrm{hr}$ upon admission has been measured. RIFLE criteria involve measurement of blood creatinine $(\mathrm{Cr})$ and monitoring of $24 \mathrm{hr}$ urine output to classify patient's state of renal injury. In this study, baseline $\mathrm{Cr}$ was determined based on patient's available record prior to ICU admission or, if such record was not available, the lowest level of $\mathrm{Cr}$ during the course of ICU admission. To determine the AKI status of a patient, we used urine GFR criteria and urine output criteria or, if the two differs, we used the one that gives a more severe AKI classification.

\section{Estimated glomerular filtration rate (eGFR)}

We calculated eGFR by using a Japanese equation [15].

$$
\begin{aligned}
& \text { For males: eGFR }\left(\mathrm{mL} / \mathrm{min} / 1.73 \mathrm{~m}^{2}\right)= \\
& \begin{aligned}
& 194 \times(\text { Serum Cr })^{-1.094} \\
& \times(\text { Age })^{-0.287} \\
& \text { For females: eGFR }\left(\mathrm{mL} / \mathrm{min} / 1.73 \mathrm{~m}^{2}\right)= 194 \times(\text { Serum Cr })^{-1.094} \\
& \times(\text { Age })^{-0.287} \times 0.739
\end{aligned}
\end{aligned}
$$

\section{Statistical analysis}

Continuous variables are presented as median and range. Groups were compared by Wilcoxon test. Analysis of the values of area under curve (AUC) of receiver operating characteristic (ROC) curves was performed to determine the significance of presepsin levels in diagnosing sepsis. The Youden index was used to identify the cutoff values for presepsin levels that may have diagnostic significance. Correlations between presepsin levels and $\mathrm{Cr}$ or eGFR were evaluated by the Spearman's rank test. All statistical analyses in this study were performed using $\mathrm{JMP}^{\circ}$ version 10 and $\mathrm{MedCalc}^{\circ}$ version 13 . P value less than 0.05 was considered statistically significant.

\section{Results}

There were 247 patients (141 men, 106 women) whose median age was 70 (range: 18-96) years old enrolled in this study. The underlying diseases of patients are shown in Table 2. The number of sepsis patients is 122 (sepsis, $\mathrm{n}=30$; severe sepsis, $\mathrm{n}=40$; septic shock, $\mathrm{n}=52$ ). The results of the bacteriological examination in sepsis patients are shown in Table 3. One hundred and twelve patients were non-AKI and we classified the patients with AKI according to the RIFLE criteria. Fifty patients were classified Risk, 36 were Injury, 42 were Failure, and 7 were Loss and ESKD. The median level of presepsin was $300 \mathrm{pg} / \mathrm{mL}$ (range: 86-4374) in the non-AKI with nonsepsis group $(\mathrm{n}=75), 831 \mathrm{pg} / \mathrm{mL}$ (range: 187-9960) in the non-AKI with sepsis group $(\mathrm{n}=37) ; 467 \mathrm{pg} / \mathrm{mL}$ (range: $71-3361)$ in the Risk non-sepsis group $(\mathrm{n}=23)$, $924 \mathrm{pg} / \mathrm{mL}$ (range: $290-16759)$ in the sepsis group $(\mathrm{n}=$ 27); $517 \mathrm{pg} / \mathrm{mL}$ (range: 144-1197) in the Injury nonsepsis group $(\mathrm{n}=9), 1451 \mathrm{pg} / \mathrm{mL}$ (range: $237-4200)$ in the sepsis group $(n=27)$. The presepsin levels in the sepsis groups were significantly higher than the nonsepsis groups ( $\mathrm{p}<0.0001, \mathrm{p}<0.01, \mathrm{p}<0.01$, respectively). The median level of presepsin was $1535 \mathrm{pg} / \mathrm{mL}$ (range: 454-8516) in the Failure non-sepsis group $(n=15)$ and $1523 \mathrm{pg} / \mathrm{mL}$ (range: $293-16764)$ in the sepsis group $(\mathrm{n}=$ 27). There was no significant differences in presepsin levels between non-sepsis group and sepsis group $(\mathrm{p}=$ 0.300 ) in the Failure group (Figure 2). As for the accuracy of diagnosing sepsis based on the level of presepsin in the ROC analysis, the AUC was 0.784 (95\% CI: 0.6830.860 ) in the non-AKI group and 0.698 (95\% CI: 0.5930.786 ) in the Risk, Injury and Failure groups combined (Figure 3). The AUC value for non-AKI group was not significantly different from that of AKI under Risk, Injury and Failure groups combined $(p=0.200)$. The Loss \& ESKD under AKI was excluded due to a very small number of patients $(n=7)$ for statistical analysis, and also due to abnormally high values of presepsin detected in the samples (see Table 4). When $670 \mathrm{pg} / \mathrm{mL}$ was used as a cutoff value for presepsin, sensitivity and specificity were $70.4 \%$, and $81.3 \%$, respectively; and when $864 \mathrm{pg} /$ $\mathrm{mL}$ was used as a cutoff value for presepsin, sensitivity and specificity were $71.3 \%$, and $63.8 \%$, respectively.

Table 1 RIFLE criteria ${ }^{11)}$

\begin{tabular}{lll}
\hline RIFLE classification & GFR criteria & Urine output criteria \\
\hline Risk & Increased serum creatinine $\times 1.5$ or GFR decrease $>25 \%$ & Urine output $<0.5 \mathrm{ml} / \mathrm{kg} / \mathrm{h} \times 6 \mathrm{hr}$ \\
Injury & Increased serum creatinine $\times 2$ or GFR decrease $>50 \%$ & Urine output $<0.5 \mathrm{ml} / \mathrm{kg} / \mathrm{h} \times 12 \mathrm{hr}$ \\
Failure & $\begin{array}{l}\text { Increased serum creatinine } \times 3 \text { or GFR decrease }>75 \%, \\
\text { serum creatinine } \geqq 4 \mathrm{mg} / \mathrm{dL}(\text { acute rise }>0.5 \mathrm{mg} / \mathrm{dL})\end{array}$ & Urine output $<0.3 \mathrm{ml} / \mathrm{kg} / \mathrm{h} \times 24 \mathrm{hr}$ or Anuria $\times 12 \mathrm{hr}$ \\
LoSS & Persistent ARF $=$ complete loss of kidney function $>4$ weeks & \\
ESKD & End Stage Kidney Disease $(>3$ months) & \\
\hline
\end{tabular}

The criteria that lead to the worst possible classification should be used. RIFLE, Risk of renal dysfunction, Injury to the kidney, Failure of kidney function, Loss of kidney function and End-stage kidney disease; GFR, Glomerular Filtration Rate; ARF Acute Renal Failure. 
Table 2 The background of patients

\begin{tabular}{lll}
\hline & 20 & 125 \\
Mrauma & 16 & \\
Metabolism, Endocrine, Allergic disease & 11 \\
Stroke, Epilepsy & 10 \\
Pneumonia & 8 \\
Respiratory disease & 7 \\
Pancreatitis & 6 \\
Non-sepsis & Heat stroke & 5 \\
& Bone and soft tissue infection & 5 \\
Burn & 5 \\
Liver disease & 4 \\
Abdominal cavity or intestinal infection & 3 \\
Drug poisoning & 3 \\
Urinary tract infection & 3 \\
Renal disease & 2 \\
Others & 17 \\
Pneumonia & 40 \\
Abdominal cavity or intestinal infection & 37 \\
Bone and soft tissue infection & 20 \\
Urinary tract infection & 7 \\
Focus unknown & Others & 6 \\
\hline
\end{tabular}

To determine how renal function affects presepsin level, correlation between presepsin and $\mathrm{Cr}$ or eGFR was evaluated using Spearman's rank test. The results showed that positive correlation between presepsin and $\mathrm{Cr}$, and negative correlation between presepsin and eGFR are significantly similar between non-sepsis and sepsis groups (Figure 4). This finding, in addition to the abnormally high presepsin levels among patients with end-stage AKI,

\section{Table 3 Results of bacteriological examination in sepsis} patients

\begin{tabular}{lc}
\hline Etiologic agent* & $\boldsymbol{n}$ \\
\hline Not detected or not examined & 36 \\
Gram negative rods & 35 \\
Gram positive coccus & 26 \\
Gram positive coccus and Gram negative bacillus & 16 \\
Gram positive coccus and Fungus & 4 \\
Fungus & 2 \\
Gram positive coccus and Gram negative bacillus and Fungus & 1 \\
Mycobacterium tuberculosis & 1 \\
Virus & \\
Total & 1
\end{tabular}

*Microbiological test result of samples taken from the presumed site of infection or blood culture.

${ }^{+}$Cytomegalovirus infection (diagnosed by Antigenemia method; C7HRP). suggests that the kidney is the main organ responsible in clearing blood of presepsin.

\section{Discussion}

Presepsin is a 13-kDa protein that is a fragment of CD14 with truncated N-terminal, the receptor for lipopolysaccharide (LPS)/LPS binding protein (LBP) complexes $[16,17]$. An in vivo study using rabbit sepsis models showed that presepsin level did not increase in the LPSinduced sepsis model whereas elevation of presepsin level was observed in a cecal ligation and puncture (CLP) sepsis model. It was speculated that the infectious stimulus led to the elevation of presepsin level. One of the production mechanisms of presepsin is related to the phagocytosis process and cleavage of membrane CD14 with lysosomal enzymes of granulocytes in an in vitro study using rabbit peritoneal leukocyte [18]. The biological function of presepsin, however, remains unknown [17]. Recently, presepsin is considered a novel marker for the diagnosis of sepsis that has been shown to increase in blood in the early stages of sepsis [19]. A multicenter prospective study by Endo et al. [10] showed that presepsin is a highly specific marker for diagnosis of bacterial infections in comparison to other sepsis markers (PCT, IL-6).

In the present study, we observed that presepsin was significantly increased in sepsis patients with non-AKI and patients with milder forms of AKI (Risk and Injury) compared to non-sepsis groups. Furthermore, the median value of presepsin increased with increasing severity of AKI both in the non-sepsis and sepsis groups. The optimal cutoff value of presepsin in non-AKI group was $670 \mathrm{pg} / \mathrm{mL}$ (a result similar to that by Endo et al. [10]) while the optimal cutoff value of presepsin in the AKI group (Risk, Injury and Failure groups combined) was significantly higher at $864 \mathrm{pg} / \mathrm{mL}$. However, when the Failure group was separately analyzed, the result is that presepsin levels among patients with sepsis are not significantly different than those with non-sepsis in this particular group of AKI patients. Despite the limited number of patients in Loss and ESKD group, the levels of presepsin were consistently and abnormally high in all patients, whether they have sepsis or not (see Table 4). It is therefore suggested that further study is needed to establish cutoff value of presepsin for each level of AKI severity to diagnose sepsis in these groups of patients.

As to how our body clears the blood of presepsin remains unknown. In this study, our data show that there is moderate positive correlation between presepsin and $\mathrm{Cr}$, and also moderate negative correlation between presepsin and eGFR in non-sepsis groups that were significantly similar to that of the sepsis groups. These results suggest that kidney is the major organ responsible in eliminating presepsin from blood. Since renal function could be considered a major determinant of presepsin 


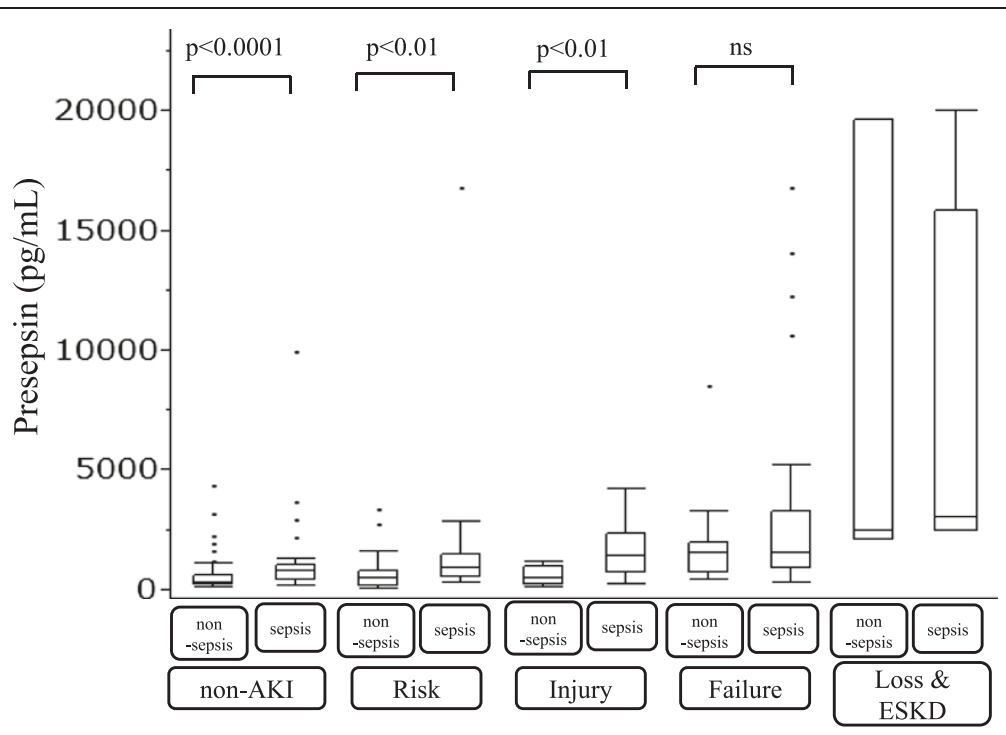

Figure $\mathbf{2}$ The comparison of the presepsin levels between non-sepsis and sepsis among non-AKI patients and patients with varying degrees of AKI. Significant difference in presepsin levels between non-sepsis and sepsis patients were observed among non-AKI and AKI under Risk and Injury groups. However, no significant deference was observed in AKI Failure group. No statistical comparison on the Loss \& ESKD group due to the small number of patients $(n=7)$ available and the abnormally high levels of presepsin detected in this group.

level, it is therefore logical that different thresholds of presepsin levels (according to the status of renal function) be applied to diagnose sepsis.

Many studies have reported that early treatment of sepsis using appropriate antibiotics improved the prognosis and increased the survival rate in severe sepsis or septic shock patients [2-4]. Moreover, patients with AKI are susceptible to many complications such as those that may be caused by sepsis; and conversely, the most common cause of AKI in critically ill patients is sepsis [20], thus making early diagnosis and treatment of sepsis very important.

Blood culture is frequently used as the "gold standard" diagnostic method for diagnosing sepsis. However, blood culture usually takes 3 to 7 days to obtain the results and frequently yields low true positive results [21]. Therefore, in general practice, the decision to treat patient for sepsis is based on the doctor's own experience (empiric therapy). Any quick tests that indicate sepsis will certainly improve

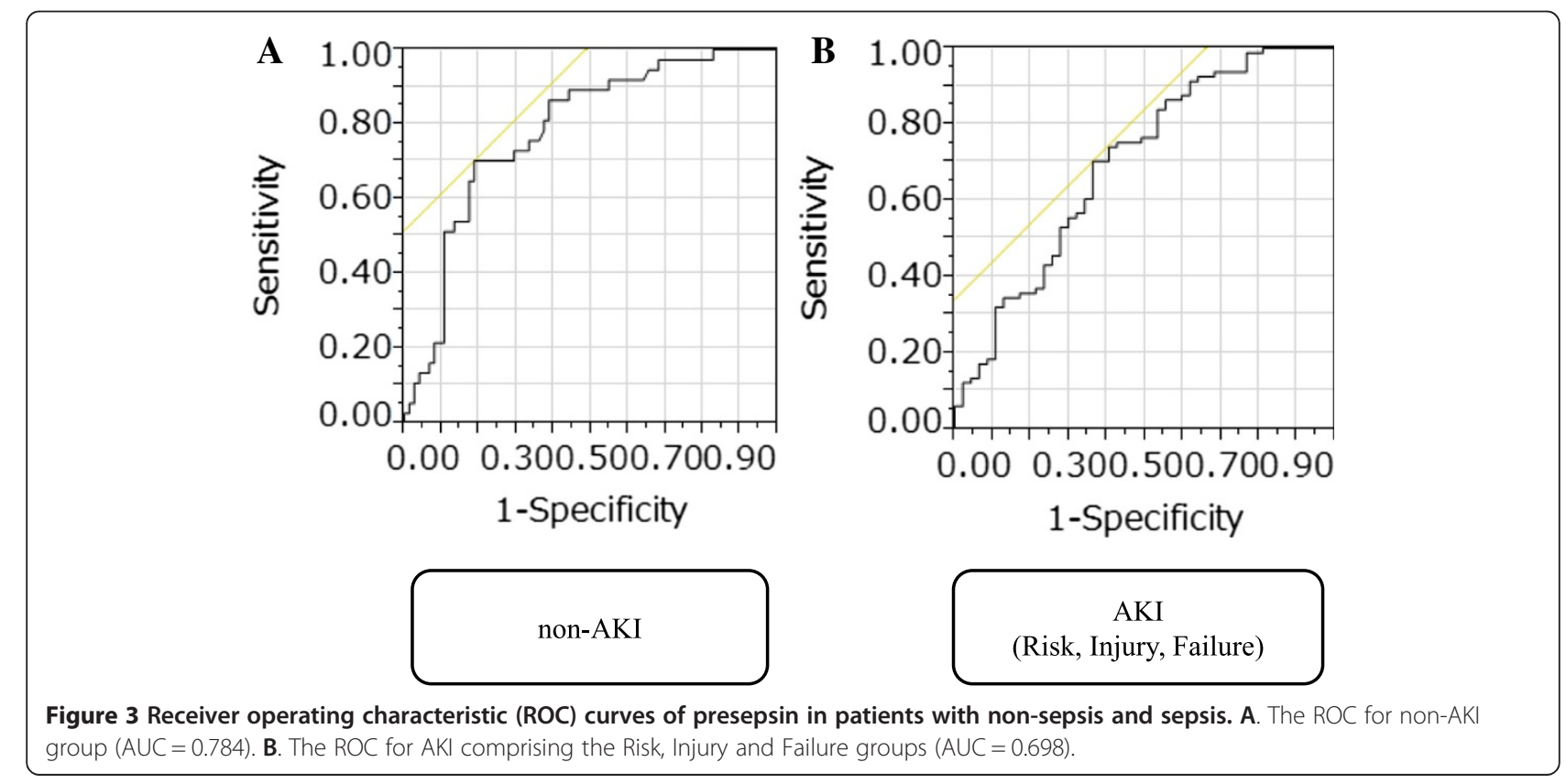


Table 4 Loss of the kidney function and End-stage renal disease character of patients

\begin{tabular}{cccc}
\hline Patient* no. & Sepsis & Presepsin $(\mathbf{p g} / \mathbf{m L})$ & $\begin{array}{c}\text { The background } \\
\text { of patients }\end{array}$ \\
\hline 1 & - & 2457 & Renal disease \\
2 & - & 2134 & Others \\
3 & - & 19633 & Urinary tract infection \\
4 & + & 20000 & Others \\
5 & + & 3424 & Pneumonia \\
6 & + & 2450 & Pneumonia \\
7 & + & 2632 & Pneumonia \\
\hline
\end{tabular}

*Patient's age ranges from 63 to 80 years old ( 3 females and 4 males).

the physician's changes of making the right diagnosis of sepsis. Presepsin testing could be one of these tests. Presepsin levels in blood are known to increase in the first $6 \mathrm{hr}$ after the onset of sepsis. These changes in concentration occurred on a much faster time scale than those observed for PCT or CRP [22]. The PATHFAST ${ }^{\bullet}$ presepsin assay reveals its result within $17 \mathrm{~min}$. This is faster than the other methods of detecting presepsin by ELISAs $[22,23]$. The PATHFAST ${ }^{\bullet}$ presepsin assay can be performed using whole blood. Whole blood samples are suitable for use in the emergency room, ICU, and the surgical operation room, thus making this present study on presepsin more meaningful.

Some limitations in our study deserve consideration. First, this retrospective single center study only involved a small number of samples; second, we did not compare presepsin to other promising biomarkers of bacterial infection that have been recently proposed, such as PCT and IL-6; third, we did not consider the effect of cellular immunity status of the patients (such as patients under chemotherapy, steroids treatment, etc.) on presepsin level; and fourth, bacterial culture was not considered in the diagnosis of sepsis. Further studies are therefore needed to address the limitations of this study cited above.

\section{Conclusions}

Blood presepsin level can be a reliable indicator of sepsis not only among non-AKI patients but also patients with less severe forms of AKI. However, it may not be a reliable indicator of sepsis in patients with a more advanced form of AKI, such as those classified under RIFLE criteria as having failure of kidney function, loss of kidney function and end-stage kidney disease.

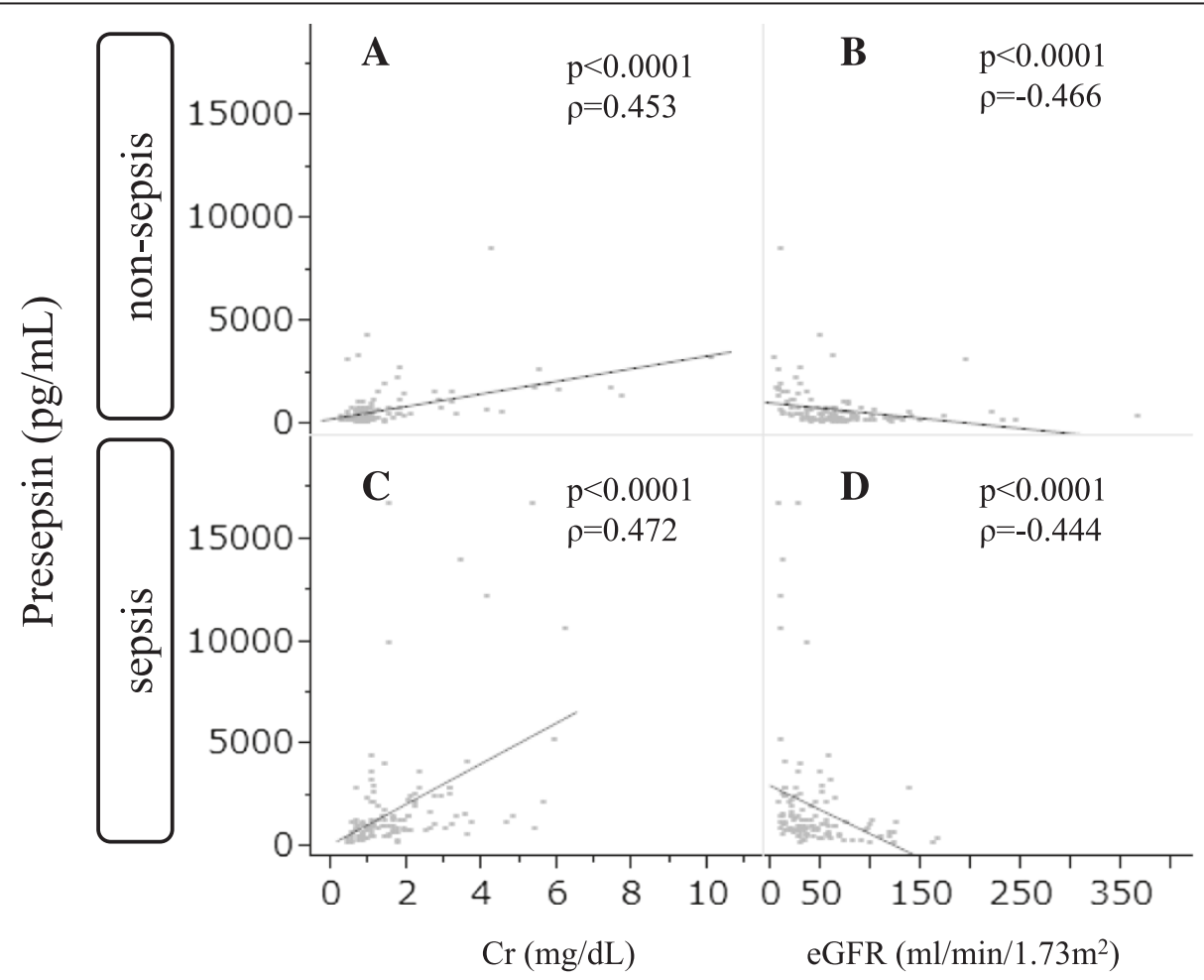

Figure 4 Spearman's rank correlation between presepsin levels and creatinine $(\mathrm{Cr})$ or between presepsin and estimated glomerular filtration rate (eGFR). The correlations between presepsin levels and $\mathrm{Cr}(\rho=0.453, p<0.0001)$ (A) or eGFR $(\rho=-0.466, p<0.0001)$ (B) in non-sepsis patients. The correlations between presepsin levels and $\operatorname{Cr}(\rho=0.472, p<0.0001)$ (C) or eGFR $(\rho=-0.444, p<0.0001)$ (D) among patients with sepsis. 


\section{Competing interests}

All authors declare that they have no competing interests.

\section{Authors' contributions}

YN contributed to the study design, data acquisition, interpretation of the results and statistical analysis, drafting of the manuscript, and critical revisions of the manuscript for its intellectual content. YR, RI and YK were involved in data acquisition and carried out the immunoassays. TN was involved in data acquisition. $\mathrm{HI}$ and AM participated in the study design, development of methodology, and helped in drafting the manuscript. All authors have read and approved the final version of the manuscript.

\section{Acknowledgments}

We sincerely thank Mr. Yoshikazu Okamura of the Mitsubishi Chemical Medience Corporation for his advice regarding this research, and Ms. Kanae Misumi of the Department of Emergency and Critical Care Medicine, Faculty of Medicine, Fukuoka University for her help in data encoding.

Received: 21 February 2014 Accepted: 24 September 2014 Published: 4 October 2014

\section{References}

1. Bone RC, Balk RA, Cerra FB, Dellinger RP, Fein AM, Knaus WA, Schein RM, Sibbald WJ: Definitions for sepsis and organ failure and guidelines for the use of innovative therapies in sepsis. The ACCP/SCCM consensus conference committee. American college of chest physicians/society of critical care medicine. Chest 1992, 101:1644-1655.

2. Battleman DS, Callahan M, Thaler HT: Rapid antibiotic delivery and appropriate antibiotic selection reduce length of hospital stay of patients with community-acquired pneumonia: link between quality of care and resource utilization. Arch Intern Med 2002, 162:682-688.

3. Kumar A, Roberts D, Wood KE, Light B, Parrillo JE, Sharma S, Suppes R, Feinstein D, Zanotti S, Taiberg L, Gurka D, Kumar A, Cheang M: Duration of hypotension before initiation of effective antimicrobial therapy is the critical determinant of survival in human septic shock. Crit Care Med 2006, 34:1589-1596.

4. Rivers E, Nguyen B, Havstad S, Ressler J, Muzzin A, Knoblich B, Peterson E, Tomlanovich M, Early Goal-Directed Therapy Collaborative G: Early goal-directed therapy in the treatment of severe sepsis and septic shock. N Engl J Med 2001, 345:1368-1377.

5. Bhatia BD, Basu S: Newer diagnostic tests for bacterial diseases. Indian J Pediatr 2007, 74:673-677.

6. Herzum I, Renz H: Inflammatory markers in SIRS, sepsis and septic shock. Curr Med Chem 2008, 15:581-587.

7. Christ-Crain M, Muller B: Procalcitonin in bacterial infections-hype, hope, more or less? Swiss Med Wkly 2005, 135:451-460.

8. Oda S, Hirasawa H, Shiga H, Nakanishi K, Matsuda K, Nakamua M: Sequential measurement of IL- 6 blood levels in patients with systemic inflammatory response syndrome (SIRS)/sepsis. Cytokine 2005, 29:169-175.

9. Abe R, Oda S, Sadahiro T, Nakamura M, Hirayama Y, Tateishi Y, Shinozaki K, Hirasawa $\mathrm{H}$ : Gram-negative bacteremia induces greater magnitude of inflammatory response than gram-positive bacteremia. Critical care (London, England) 2010, 14:R27.

10. Endo S, Suzuki Y, Takahashi G, Shozushima T, Ishikura H, Murai A, Nishida T, Irie $Y$, Miura M, Iquchi $H$, Fukui $Y$, Tanaka $K$, Nojima T, Okamura $Y$ : Usefulness of presepsin in the diagnosis of sepsis in a multicenter prospective study. J Infec Chemother Official J Japan Soc Chemotherap 2012, 18:891-897.

11. Bellomo R, Ronco C, Kellum JA, Mehta RL, Palevsky P, Acute Dialysis Quality Initiative w: Acute renal failure - definition, outcome measures, animal models, fluid therapy and information technology needs: the second international consensus conference of the acute dialysis quality initiative (ADQI) group. Critical care (London, England) 2004, 8:R204-R212.

12. Kurihara T, Yanagida A, Yokoi H, Koyata A, Matsuya T, Ogawa J, Okamura Y, Miyamoto D: Evaluation of cardiac assays on a benchtop chemiluminescent enzyme immunoassay analyzer, PATHFAST. Anal Biochem 2008, 375:144-146.

13. Okamura Y, Yokoi H: Development of a point-of-care assay system for measurement of presepsin (sCD14-ST). Clinica Chim Acta Int J Clinical Chem 2011, 412:2157-2161.
14. Ricci Z, Ronco C, D'Amico G, De Felice R, Rossi S, Bolgan I, Bonello M, Zamperetti N, Petras D, Salvatori G, Dan M, Piccinni P: Practice patterns in the management of acute renal failure in the critically ill patient: an international survey. Nephrol dialysis Transplant Official Publ European Dialysis Transpl Assoc European Renal Assoc 2006, 21:690-696.

15. Matsuo S, Imai E, Horio M, Yasuda Y, Tomita K, Nitta K, Yamagata K, Tomino Y, Yokoyama H, Hishida A, Collaborators developing the Japanese equation for estimated GFR: Revised equations for estimated GFR from serum creatinine in Japan. Am J Kidney Dis Official J Nat Kidney Found 2009, 53:982-992.

16. Furusako SSK: Methods for detecting human low molecular weight CD14. United States Patent 2008, B2:US7465547.

17. Furusako SSK, Hirose J: Soluble CD14 antigen. United States Patent 2009 B2:US7608684.

18. Naito K: Method for evaluation of function of phagocyte. United States Patent 2011, A1:US0086381.

19. Shozushima T, Takahashi G, Matsumoto N, Kojika M, Okamura Y, Endo S: Usefulness of presepsin (sCD14-ST) measurements as a marker for the diagnosis and severity of sepsis that satisfied diagnostic criteria of systemic inflammatory response syndrome. J Infect Chemotherap Official J Japan Soc Chemotherap 2011, 17:764-769.

20. Murugan R, Kellum JA: Acute kidney injury: what's the prognosis? Nat Rev Nephrol 2011, 7:209-217.

21. Rangel-Frausto MS, Pittet D, Costigan M, Hwang T, Davis CS, Wenzel RP: The natural history of the systemic inflammatory response syndrome (SIRS). A prospective study. JAMA J Am Med Assoc 1995, 273:117-123.

22. Yaegashi Y, Shirakawa K, Sato N, Suzuki Y, Kojika M, Imai S, Takahashi G, Miyata M, Furusako S, Endo S: Evaluation of a newly identified soluble CD14 subtype as a marker for sepsis. I Infect Chemotherap Official J Japan Soc Chemotherap 2005, 11:234-238.

23. Shirakawa K, Naitou K, Hirose J, Takahashi T, Furusako S: Presepsin (sCD14-ST): development and evaluation of one-step ELISA with a new standard that is similar to the form of presepsin in septic patients. Clinical Chem Lab Med CCLM / FESCC 2011, 49:937-939.

\section{doi:10.1186/1471-2253-14-88}

Cite this article as: Nakamura et al:: Usefulness of presepsin in the diagnosis of sepsis in patients with or without acute kidney injury. BMC Anesthesiology 2014 14:88.

\section{Submit your next manuscript to BioMed Central and take full advantage of:}

- Convenient online submission

- Thorough peer review

- No space constraints or color figure charges

- Immediate publication on acceptance

- Inclusion in PubMed, CAS, Scopus and Google Scholar

- Research which is freely available for redistribution

Submit your manuscript at www.biomedcentral.com/submit
C Biomed Central 